\title{
LAS ACCIONES FORESTALES EN EL SENO DE LA PAC. CONSECUENCIAS PARA ANDALUCÍA DEL PROGRAMA DE REFORESTACIÓN'
}

\author{
Rocío SILVA PEREZ*
}

\section{INTRODUCCIÓN}

Como es sabido, la privatización del patrimonio público rústico ha sido una constante a lo largo de la historia (LÓPEZ ESTUDILLO, 1992): roturaciones arbitrarias, en gran parte legalizadas; usurpaciones silenciadas por parte de la Administración; ventas mediante subastas en el período desamortizador, etc., se han saldado en un espectacular avance de las tierras de cultivo y en un protagonismo desmedido de los montes gestionados por los propietarios particulares en la estructura forestal actual. Paralelamente, los sucesivos intentos de corregir esta dinámica (Ordenanzas para la restitución de los bienes despojados decretadas por Alfonso XI en 1323 y por Pedro I en 1331; relación de bienes exceptuados de las desamortizaciones del S. XIX; repetidos intentos de incrementar el patrimonio público forestal y de involucrar a los propietarios particulares en la obra reforestadora, etc.) no han dado los resultados previstos (LÓPEZ ESTUDILLO, 1992, 66 y GÓMEZ MENDOZA y MATA OLMO, 1992). Sin embargo, hoy parece que estamos asistiendo a una dinámica diferente, y hasta cierto punto paradógica (GÓMEZ MENDOZA, 1992, 80) en la que el monte y los aprovechamientos forestales aparecen, por una parte, como alternativas de sustitución para las tierras ocupadas por cultivos excedentarios y, por otra, como elementos a tener en cuenta en la necesaria diversificación económica del mundo rural. En resumidas cuentas, el contexto socio-político actual -y, concretamente, las medidas emanadas de la política agra-

* Profesora Asociada. Universidad de Huelva.

1. Este trabajo constituye una continuación del informe sobre La reconversión del suelo agricola a forestal en zonas de agricultura marginal, encargado en 1994 por la Unión Agraria de Explotaciones Familiares de Andalucía. Una reflexión sobre el alcance del programa comunitario de reforestación a nivel nacional ha sido presentada por esta misma autora al XIV Congreso Nacional de Geografía bajo el título De la deforestación a la reconversión de terrenos agrícolas en forestales. Un análisis crítico. 
ria europea- están propiciando la reforestación de tierras de cultivo antaño roturadas y, como resultado de ello, el incremento de los montes gestionados por los propietarios privados.

Teniendo en cuenta estas consideraciones, este trabajo pretende iniciar una reflexión sobre las consecuencias que pudiera tener este cambio de perspectiva histórica en la gestión de los montes andaluces. Para ello, se analiza la situación actual del sector, en relación a las reforestaciones ejecutadas en la historia reciente -con especial atención a las efectuadas por la iniciativa privada- y a las previsiones recogidas en el Plan Forestal Andaluz. Por último, se relatan las novedades y posibles alicientes ofertados por el nuevo programa de reforestación comunitario a las repoblaciones llevadas a cabo por los propietarios particulares.

\section{EL SECTOR FORESTAL EN ANDALUCÍA}

En los últimos años se ha venido detectando un relativo incremento del valor de las producciones forestales en la economía agraria andaluza, que se puede explicar por la crisis que atraviesan las producciones agrícolas, por el efecto de los programas que incentivan el abandono de tierras arables y por el empuje reforestador conducido tradicionalmente por la iniciativa pública y, según nuestra hipótesis, ahora también por la iniciativa privada. Así por ejemplo, la participación de las producciones agrícolas en la Producción Final Agraria andaluza (en adelante PFA) descendió - en pesetas constantes- cerca de un $12 \%$ entre 1992 y 1993, cuando las producciones ganaderas incrementaron su participación en torno al $2 \%$ y las forestales lo hicieron alrededor del $4 \%$. Con todo, la contribución del subsector forestal a la economía agraria regional continúa siendo un tanto anecdótica: 16.242 millones de pesetas corrientes de 1993 (apenas el $2 \%$ de la PFA) ${ }^{2}$, frente a 575.017 millones de pesetas de contribución del subsector agrícola (el $76 \%$ de la PFA) y a 136.958 millones pesetas de participación del subsector ganadero.

La intrascendencia económica del sector forestal contrasta con la extensión superficial que tienen los montes en Andalucía: unos 4,6 millones de hectáreas que representan más del $50 \%$ del territorio regional. Así pues, de la comparación de la superficie ocupada por los montes con el valor de las producciones forestales podemos extraer unas primeras conclusiones que no hacen sino ratificar una situación que es bien conocida por todos: a) la importante representación de los terre-

2. La participación de los distintos aprovechamientos en la riqueza generada por los montes andaluces es la siguiente: caza $(45 \%)$, madera $(16 \%)$, bellota en montanera $(11 \%)$, corcho $(9 \%)$ y piñón $(7 \%)$. Si prescindimos de la caza, y nos centramos en los aprovechamientos netamente forestales, estos porcentajes quedan como sigue: madera $(31,4 \%)$, bellota en montanera $(22 \%)$, corcho $(18 \%)$, piñón $(13,4 \%)$, Ieña $(7 \%)$ y castañas $(5,4 \%)$. 
nos desarbolados en los montes andaluces, b) su escasa productividad, y c) el hecho de que las masas forestales de la región deparen más beneficios sociales que directamente económicos.

En el cuadro n 1 hemos reflejado la evolución de la superficie forestal andaluza en relación a las previsiones efectuadas por el Plan Forestal. En el mismo se puede apreciar la importancia que siguen teniendo los terrenos desarbolados tras varios años de aplicación del Plan. Como es sabido, el Plan Forestal prevee un incremento de la superficie forestal arbolada de más de 1,25 millones de hectáreas en sus sesenta años de vigencia; lo que supone un ritmo anual de reforestación de unas 21.000 Has. Por su parte, la superficie desarbolada debería descender, según

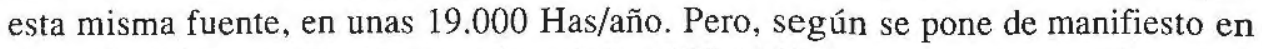
el cuadro $n^{\circ} 1$, los resultados del período 1988-1992 (un incremento medio anual de la superficie arbolada de poco más de 9.000 Has. y un retroceso similar de la

CUADRO № 1

\section{LA DISTRIBUCIÓN DE LA SUPERFICIE FORESTAL ANDALUZA EN 1988 Y EN 1992 EN RELACIÓN A LAS PREVISIONES DEL PLAN FORESTAL ANDALUZ}

\begin{tabular}{|c|c|c|c|c|}
\hline Unidades de Vegetación & $\begin{array}{c}\text { Año } 1988 \\
\text { (miles Has.) }\end{array}$ & $\begin{array}{c}\text { Año } 1992 \\
\text { (miles Has.) }\end{array}$ & $\begin{array}{c}\text { Variación } \\
\text { media anul } \\
1988-1992 \\
\text { (Has.) }\end{array}$ & $\begin{array}{c}\text { Variación } \overline{\mathrm{x}} \\
\text { anual prevista } \\
\text { en el plan } \\
\text { andaluz (Has.) }\end{array}$ \\
\hline 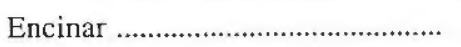 & 845,7 & 826,79 & 272,5 & $1.475,85$ \\
\hline 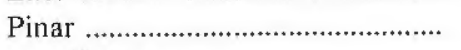 & 756,7 & 778,73 & $5.507,0$ & $2.378,50$ \\
\hline 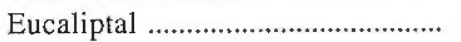 & 267,3 & 249,28 & $-4.405,0$ & $-1.404,20$ \\
\hline 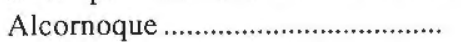 & 183,6 & 185,51 & 477,5 & 873,00 \\
\hline Mezcla de quercus y frondosas ... & 161,0 & 173,77 & $3.192,0$ & $7.321,00$ \\
\hline Mezcla de pinos y quercus .......... & 131,5 & 148,65 & $4.288,5$ & $8,863,00$ \\
\hline 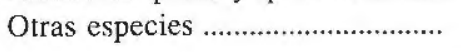 & 36,5 & 39,47 & 742,5 & $1.452,60$ \\
\hline Superficie Forestal Arbolada ....... & $2.385,3$ & $2.422,20$ & $9.222,0$ & $20.962,00$ \\
\hline Matorral mediterráneo .................... & 964,8 & 926,45 & $-9.587,0$ & $-9.852,00$ \\
\hline Tierras agrícolas marginales ........ & 623,2 & 622,80 & $-100,0$ & $-9.691,00$ \\
\hline Formaciones herbáceas ................ & 426,9 & 429,15 & 562,0 & 747,00 \\
\hline Matorral mediterráneo noble ....... & 216,2 & 215,80 & $-100,0$ & $-477,00$ \\
\hline Zonas húmedas .............................. & 34,7 & 34,70 & - & - \\
\hline Superficie Forestal desarbolada... & $2.265,8$ & $2.228,90$ & $-9.225,0$ & $-19.273,30$ \\
\hline Superficie Forestal Total ............... & $4.651,1$ & $4.651,10$ & - & $1.688,00$ \\
\hline
\end{tabular}

Fuente: Plan Forestal Andaluz, 1989, y Anuario de Estadísticas Agrarias y Pesqueras de Andalucia, 1992. Elaboración propia. 
desarbolada) distan mucho de aproximarse a estas previsiones. Por otra parte, la superficie de montes, que según el Plan debería incrementarse cada año en torno a 1.700 hectáreas (más de 101.000 Has. transcurridos sesenta años), ha permanecido invariable en el período analizado; lo que demuestra, nuevamente, la disparidad existente entre las previsiones y los resultados.

El avance de la superficie arbolada se ha realizado, básicamente, a costa del matorral mediterráneo; lo que está de acuerdo con las previsiones. En cambio, el retroceso de las áreas de agricultura marginal ha sido muy escaso: una media de $100 \mathrm{Has}$.año, que dista mucho de aproximarse a las 9.900 Has. anuales previstas en el Plan Forestal Andaluz.

En otro orden de cosas, hemos de señalar que el Plan Forestal ofrece una valoración un tanto disminuida de la extensión territorial que tienen en Andalucía las áreas marginales: unas 623.000 Has., cuando según el S1NAMBA los suelos improductivos desde el punto de vista agrícola ocupan alrededor de 2,5 millones de hectáreas (AGENCIA DE MEDIO AMB1ENTE, 1990, 113). No obstante, pese a la disparidad de las cifras que ofrecen, ambas fuentes ponen de manifiesto la importancia que tienen las zonas de agricultura marginal -cuyo uso más adecuado es el forestal- en el conjunto de la región, y coinciden en señalar la necesidad de proceder a su reforestación. Pero los resultados conseguidos en relación a este punto han sido muy limitados, debido, sobre todo, a los escasos incentivos ofertados tradicionalmente por los programas de reforestación a la iniciativa privada, propietaria de la mayor parte de los cultivos desarrollados en áreas marginales para la agricultura. Situación, ésta última, que puede que se esté modificando como resultado de la aplicación del programa de reconversión de terrenos agrícolas en forestales contenido en el Reglamento Comunitario 2080/1992.

La escasa aportación de las producciones forestales a la economía agraria andaluza se explica, asimismo, por la reducida productividad de sus montes. Según se puede apreciar en el cuadro $\mathrm{n}^{\circ} 2$, la productividad maderera de la superficie boscosa andaluza $\left(0,83 \mathrm{~m}^{3} / \mathrm{Ha}\right.$.) se reduce a la mitad de la productividad media española $\left(1,6 \mathrm{~m}^{3} / \mathrm{Ha}\right.$.), y no admite comparación con la productividad maderera de los bosques de la Cornisa Cantábrica $\left(5 \mathrm{~m}^{3} / \mathrm{Ha}\right.$. en Galicia y $2,2 \mathrm{~m}^{3} / \mathrm{Ha}$. en Asturias). La productividad andaluza en los restantes productos forestales se sitúa por encima de la media española, siendo de destacar la mayor rentabilidad de las superficies ocupadas por castaños y pinos piñoneros $(1.980 \mathrm{Kg}$. de castañas/Ha. y $35,4 \mathrm{Kg}$. de piñones/Ha., los valores más altos del conjunto nacional). Con todo, la productividad de la superficie ocupada por las quercíneas $(718 \mathrm{Kg}$. de corcho/Ha. de alcornoque y $456 \mathrm{Kg}$. de bellota para montanera/Ha. de quercíneas), aunque también sobrepasa la media española, no guarda relación ni con la extensión superficial de estas especies en Andalucía (cuadro $n^{\circ} 1$ ), ni con la importancia que tienen las áreas de dehesa en esta Comunidad: alrededor de 735.000 Has., más del $35 \%$ de la superficie forestal arbolada (AGENCIA DE MEDIO AMBIENTE, 1993, 216). 
CUADRO № 2

LA PRODUCTIVIDAD DE LOS MONTES ANDALUCES

\begin{tabular}{lccc}
\hline Productos & Andalucía & España & Otras CC.AA. \\
\hline $\begin{array}{l}\text { Madera (m3/Ha. de superficie } \\
\text { boscosa)*............................ }\end{array}$ & 0,83 & 1,60 & $\begin{array}{c}\text { Galicia: } 5,0 \\
\text { Asturias: } 2,2\end{array}$ \\
$\begin{array}{l}\text { Leña (estéreos/Ha. de superf. } \\
\text { boscosa) ............................... }\end{array}$ & 0,40 & 0,34 & Galicia: 1,4 \\
$\begin{array}{l}\text { Corcho (Kg./Ha. de alcornocal) .. } \\
\begin{array}{l}\text { Bellota en montanera (Kg./Ha. } \\
\text { de quercus) .............................. }\end{array}\end{array}$ & 718,60 & 723,50 & Extremadura: $19.002,0$ \\
$\begin{array}{l}\text { Piñón (Kg./Ha. de pino piñonero) } \\
\text { Castaña (Kg./Ha. de castaños) ..... }\end{array}$ & 356,50 & 291,50 & Extremadura: $38.733,0$ \\
\hline
\end{tabular}

* Según la Encuesta de Estructura Forestal, la superficie hoscosa está constituida por aquella parte de la superficie forestal cubierta por una asociación vegental en la que predominen árboles y arbustos susceptibles de producir madera u otros productos forestales.

Fuente: Anuario de Estadística Agraria, 1992. Elaboración propia.

Finalmente, y sin ánimos de ser exhaustivos, la escasa participación de las producciones forestales en la economía agraria andaluza denota la funcionalidad eminentemente socio-protectora de los montes de la región.

Como es sabido, además de los beneficios económicos que aportan a sus propietarios, las superficies boscosas proporcionan una serie de beneficios indirectos (protección, ocio y esparcimiento, equilibrio territorial en base a la diversificación de rentas como pretenden los últimos programas, etc.) que revierten en toda la sociedad; de ahí el que tradicionalmente se haya considerado que la propiedad pública resulta ser más adecuada que la privada para una gestión integral de los montes (FERNANDEZ TOMAS, 1989, 277). En relación a este punto, el Plan Forestal prevee un incremento de los montes públicos en torno a las 23.000 hectáreas anuales (más de 1,4 millones de hectáreas en su sesenta años de vigencia) a costa de los montes gestionados por los propietarios privados. Asimismo, se estima un incremento medio de los consorcios y convenios con particulares de unas 4.000 Has./año (240.000 Has. transcurridos sesenta años). Pero estas previsiones tampoco se han cumplido en los primeros años de aplicación del Plan tal como pone de manifiesto el cuadro $n^{0} 3$. Nuestra hipótesis, en relación a este punto, es que la superficie forestal en régimen privado puede que se incremente en años 
venideros a costa de las tierras de cultivo ${ }^{3}$, debido, entre otras, a la conjunción de las siguientes circunstancias (SILVA PEREZ, 1995):

- La progresiva reducción de los precios agrarios a raíz de las medidas liberalizadoras decretadas en la Ronda Uruguay del GATT.

- El previsible incremento en el precio de los productos forestales como consecuencia, por una parte, de la reducción de los países exportadores ${ }^{4}$ y, por otra, del déficit maderero de la Unión Europea, y

- Los incentivos que oferta el programa de reforestación (Reglamento 2080/ 92) a la reconversión de terrenos agrícolas en forestales.

En resumidas cuentas, de confirmarse nuestra hipótesis los montes gestionados por la iniciativa privada seguirán teniendo una gran relevancia en la superficie forestal andaluza; y ello aún presuponiendo que las previsiones recogidas en el Plan Forestal se cumplan al final del período. Resulta, pues, necesario, habilitar una serie de medidas que consigan involucrar a los propietarios privados en la preservación de los beneficios sociales que los montes proporcionan.

\section{CUADRO № 3}

\section{LA DISTRIBUCION DE LA PROPIEDAD FORESTAL ANDALUZA EN 1988 Y 1992} EN RELACION A LAS PREVISIONES DEL PLAN FORESTAL

\begin{tabular}{lcccc}
\hline Propiedad de los montes & $\begin{array}{c}\text { Año 1988 } \\
\text { (x 1.000 has.) }\end{array}$ & $\begin{array}{c}\text { Año 1992 } \\
\text { (x 1.000 has.) }\end{array}$ & $\begin{array}{c}\text { Variación } \\
\text { media anul } \\
1988-1992 \\
\text { (Has.) }\end{array}$ & $\begin{array}{c}\text { Variación } \\
\text { anual prevista } \\
\text { en el plan forestal } \\
\text { andaluz (Has.) }\end{array}$ \\
\hline $\begin{array}{l}\text { Montes del Estado .......... } \\
\begin{array}{c}\text { Montes de las Entidades } \\
\text { Locales ....................... }\end{array}\end{array}$ & 542,4 & 605,7 & 15.825 & 23.966 \\
$\begin{array}{c}\text { M. particulares consorc. } \\
\text { o conveniados .............. }\end{array}$ & 711,5 & 711,5 & - & $\mathrm{s} / \mathrm{d} *$ \\
$\begin{array}{c}\text { M. particulares de } \\
\text { administr. particular....... }\end{array}$ & $3.246,8$ & $3.187,1$ & -14.900 & -23.966 \\
\hline
\end{tabular}

* El Plan prevee un incremento de los Montes de Utilidad Pública de unas 133.000 Has. Fuente: Plan Forestal Andaluz, 1989 y Anuario de Estadísticas Agrarias y Pesqueras de Andalucía, 1992. Elaboración propia.

3. Si bien en un principio este proceso sólo afectaría a las áreas de agricultura marginal, que ya forman parte de la superficie de montes, a medida que avance la crisis agraria podría llegar a alcanzar a las mejores tierras de cultivo, incluidos algunos regadíos, como ya señalaba Sumpsi un año antes de la aprobación de la última reforma de la PAC (SUMPSI, 1991, 58).

4. Según previsiones de la FAO, los países netamente exportadores de productos forestales se reducirán en tomo al $70 \%$ en el período comprendido entre 1989 y el año 2000 (MARRACO, 1989, 18). 


\section{LAS REPOBLACIONES FORESTALES ANDALUZAS EN EL MARCO DE LA PAC}

Pese a carecer de una política forestal específica, la Unión Europea ha venido financiado acciones netamente forestales bajo el soporte jurídico de determinadas líneas de ayuda cuyo objetivo principal es la mejora de las estructuras Agrarias, siendo de destacar, a este respecto, los siguientes programas:

- El programa de mejora de la eficacia de las estructuras agrarias (Reglamento 797/1985) introduce en su título VI una línea de fomento de las inversiones forestales en las explotaciones agrarias.

- El programa de retirada de tierras de la producción (Reglamento 1094/1988) incentiva la repoblación forestal entre las alternativas de abandono con primas superiores a las de otras opciones de sustitución.

- El programa de jubilación anticipada (Reglamento 1096/1988) oferta a los agricultores que hayan optado por la repoblación forestal una prima adicional de $250 \mathrm{ECUs} / \mathrm{Ha}$. a percibir durante veinte años, que se añade a la subvención por cese de actividad (3.000 ECUs/Ha., por un máximo de diez años).

- El Reglamento 1118/1988, relativo a la acción común para promover el desarrollo de las zonas desfavorecidas en España, incluye la lucha contra la erosión y la mejora forestal entre sus líneas de ayuda.

- Asimismo, de los ocho ejes de intervención que conforman el Marco Comunitario de Apoyo 1989-1993 para las regiones Objetivo 1 (categoría en la que se encuadra Andalucía), dos contienen medidas forestales: el cuarto, Agricultura y Desarrollo Rural, y el quinto, Infraestructura de apoyo a las actividades económicas.

- Finalmente, la última modificación de la política agraria europea (Reforma MacSharry, 1992) introduce importantes incentivos al proceso reforestador: sustitución de las subvenciones vía precios por ayudas directas a las rentas previo abandono del $15 \%$ de la superficie productiva; inclusión del abandono de larga duración (20 años) en el denominado Programa Agroambiental; inicio de un programa específico de reforestación de superficies agrarias, etc.

La estrategia adoptada por la Junta de Andalucía en relación a estas líneas ha sido la de recabar fondos comunitarios para la financiación de sus propios programas de reforestación; lo que a veces se ha resuelto con problemas dado que, a diferencia de lo señalado para la Unión Europea, el Gobierno Andaluz sí dispone de una política forestal específica, relativamente desvinculada de los programas de política agraria. 
Los programas de la PAC con incidencia en el sector forestal aplicados en Andalucía pueden ser estructurados en tres grupos:

1. Aquéllos que requieren la participación financiera del agricultor, de exclusiva incidencia en las propiedades particulares: programa de retirada de tierras, jubilación anticipada y ayudas a las inversiones forestales en las explotaciones agrarias.

2. Los que están financiados en su totalidad con fondos públicos (Junta de Andalucía, Gobierno Central, FEDER y FEOGA-Orientación), aplicados en su totalidad en los montes gestionados por la Administración Forestal (Montes del Estado y Montes Consorciados, bien sean de las Entidades Locales o de propietarios particulares), entre los que destacan los siguientes:

- El Programa Operativo "Plan Forestal Andaluz", aprobado el 12 de diciembre de 1990, con una vigencia de cuatro años (mayo de 1990-diciembre de 1993).

- El Programa Operativo "Jaén-Granada" (31 de enero de 1991-31 de diciembre de 1993), que incluye a las repoblaciones forestales entre sus líneas de ayuda, y

- Las acciones forestales contenidas en el Reglamento 1118/88 (lucha contra la erosión y repoblaciones forestales).

3. El último programa de reforestación (Reglamento 2080/92), financiado en su totalidad con fondos públicos, que incluye una serie de acciones forestales aplicables tanto a las propiedades públicas como a las privadas formaría, finalmente, el tercer grupo.

El análisis detallado de las repercusiones de los dos primeros grupos en el conjunto de la región sobrepasa los objetivos de este trabajo. Con todo, hemos de señalar la escasa incidencia que han tenido hasta ahora en Andalucía aquellos programas que requieren la participación financiera del propietario. Así por ejemplo, si bien desconocemos qué porcentaje de los agricultores acogidos a la jubilación anticipada han optado por la repoblación forestal, la superficie reforestada por este concepto ha debido ser mínima a tenor de la escasa aceptación de este programa en Andalucía: tan sólo 59 explotaciones implicadas en el período 1989-1993. Otro tanto cabría decir de la incidencia del programa de retirada de tierras, con menos de 2.000 Has. afectadas entre 1989 y 1992, el $25 \%$ de las cuales se destinaron a repoblación forestal. Finalmente, las reforestaciones realizadas a raíz de la aplicación del programa de fomento de las inversiones forestales en las explotaciones agrarias (Título VI del Reglamento 797/85) no son comparables a las practicadas en terrenos públicos. 
Según se pone de manifiesto en el cuadro $n^{0} 4$, las repoblaciones forestales, tanto públicas como privadas, han experimentado un importante retroceso a partir de 1985; y, pese a la reducción de las hectáreas afectadas por los incendios forestales (excepción hecha de 1991), la superficie repoblada a efectos reales se ha visto muy mermada y, en algunos años (1985, 1986 y 1991) las hectáreas devastadas por los incendios sobrepasan a las repobladas (Columna $E$ del cuadro $n^{\circ} 4$ ). Pero lo que más nos interesa resaltar, en relación al tema que nos ocupa, es que las repoblaciones realizadas por los propietarios particulares se sitúan muy por debajo de las efectuadas por la Administración Pública. Así, apenas la cuarta parte de las 565.000 hectáreas repobladas en el período 1970-1992 fueron ejecutadas en propiedades particulares; porcentaje éste que se reduce al 17\% desde nuestra integración en la Unión Europea.

Las repoblaciones efectuadas por el sector forestal privado mediante subvención pública se amparan en el Programa de Fomento de las Producciones Forestales, basado inicialmente en lo tipificado en la Ley y Reglamento de Montes, y posteriormente en la Ley de Fomento de las Producciones Forestales del Ministe-

\section{CUADRO № IV \\ REPOBLACIONES E INCENDIOS FORESTALES EN ANDALUCÍA. SERIE HISTÓRICA}

\begin{tabular}{|c|c|c|c|c|c|}
\hline Años & A & B & $\mathrm{C}$ & $\mathrm{D}$ & E \\
\hline $1970-1974 \ldots \ldots \ldots$ & 117.104 & 50.369 & 167.473 & 26.810 & 140.663 \\
\hline 1975-1979 .............. & 99.322 & 72.483 & 171.805 & 57.396 & 114.409 \\
\hline $1980-1980 \ldots \ldots \ldots \ldots$. & 89.977 & 16.401 & 106.398 & 42.552 & 63.864 \\
\hline 1985 & 13.484 & 551 & 14.035 & 20.868 & -6.833 \\
\hline 1986 & 9.036 & 3.155 & 12.191 & 18.622 & -6.071 \\
\hline 1987 & 10.801 & 1.774 & 12.575 & 6.480 & 6.095 \\
\hline 1988 & 12.667 & 2.677 & 15.344 & 6.598 & 8.746 \\
\hline 1989 & 13.384 & 1.335 & 15.019 & 7.882 & 7.137 \\
\hline 1990 & 17.228 & 2.534 & 15.762 & 3.762 & 12.000 \\
\hline 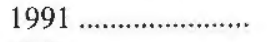 & 12.642 & 1.939 & 14.581 & 45.029 & -30.448 \\
\hline 1992 & 13.593 & 2.271 & 15.864 & 7.157 & 8.717 \\
\hline 1970-1992 ............... & 409.238 & 115.849 & 564.727 & 242.796 & 321.931 \\
\hline
\end{tabular}

A) Hectáreas repobladas por la Administración Forestal.

B) Hectáreas repobladas en montes privados mediante subvención.

C) Total repoblaciones forestales $(\mathrm{A}+\mathrm{B})$.

D) Superficie arbolada afectada por incendios (Has.).

E) Reforestaciones reales (C-D).

Fuente: Medio Ambiente en Andalucía. Informe 1989 y Anuario de Estadísticas Agrarias y Pesqueras de Andalucía, 1992. Elaboración propia. 
rio de Agricultura, Pesca y Alimentación. Este programa, aplicado en Andalucía desde 1969, contempla las siguientes líneas de ayuda: repoblaciones forestales, trabajos culturales en terrenos poblados con especies del género quercus, apertura y conservación de cortafuegos, mejora de la infraestructura viaria y de defensa contra incendios, y redacción de proyectos de ordenación y planes técnicos. Desde 1984 estas líneas de ayuda se articulan en dos subprogramas denominados de Fomento de la Producción de Madera (montes de chopo y eucalipto, fundamentalmente) y de Fomento de las Producciones Forestales no Maderables (principalmente quercíneas) ${ }^{5}$; a los que se añade en 1989 (Orden de la Consejería de Agricultura y Pesca de 7 de abril de 1989) una línea específica de Fomento y Mejora de Alcornocales y Encinares, que viene a complementar las ayudas dispensadas por el Ministerio de Agricultura a las producciones no maderables. Desde la integración española en la Unión Europea, todas estas líneas de ayuda han estado cofinanciadas con fondos imputables al FEOGA-Orientación: Título VI del Reglamento 797/1985, sustituido con posterioridad por el Reglamento 1609/1989.

En el cuadro $n^{0} 5$ aparecen reflejadas las repoblaciones forestales efectuadas al amparo del programa señalado en el período 1986-1993. Nos interesa resaltar la escasa cuantía de las ayudas dispensadas (una media de 40.000 pesetas/hectáreas) en comparación con las ofertadas por el reciente programa de reforestación comunitario, tal como tendremos ocasión de comprobar en capítulos posteriores. Pero demás, la iniciativa privada ha tenido que sufragar entre el 50 y el $60 \%$ de los gastos imputables al proceso reforestador; lo que, en nuestra opinión, ha incidido de forma negativa en su incidencia territorial, sobre todo si tenemos en cuenta que los beneficios económicos generados por las repoblaciones, que son los que más interesan a los propietarios particulares, sólo se obtienen en el medio-largo plazo. Hemos de señalar, asimismo, el protagonismo que adquieren las repoblaciones efectuadas con especies maderables en relación a las no maderables: más de 13.000 bectáreas repobladas con eucaliptos y chopos, frente a 7.400 hectáreas ocupadas por quercíneas.

Se confirman, pues, los escaso incentivos ofertados tradicionalmente por los programas de reforestación a la iniciativa privada que ya señalábamos en páginas anteriores. Por otra parte, el papel desempeñado por las especies de crecimiento rápido en las repoblaciones privadas responde a una lógica un tanto economicista que se aparta de las recomendaciones del Plan Forestal; lo que, a nuestro entender, resulta preocupante, sobre todo si tenemos en cuenta que la mayor parte de los montes andaluces están gestionados por propietarios particulares y que, en consecuencia, debería recaer en ellos la salvaguarda de los beneficios indirectos que los montes proporcionan.

5. Con anterioridad a la publicación del R.D. 1552/1984, por el que se establece el Programa Nacional de Ordenación y Mejora de Explotaciones Ganaderas Extensivas, el Programa de Fomento de las Producciones Forestales contemplaba, asimismo, una línea de ayudas para la mejora integral de pastizales. 


\section{CUADRO $\mathrm{V}$}

REFORESTACIONES EFECTUADAS EN MONTES LOS PRIVADOS ANDALUCES MEDIANTE SUBVENCIÓN PÚBLICA

\begin{tabular}{|c|c|c|c|c|c|c|}
\hline Años & & Hectáreas & $\begin{array}{l}\text { Inversión } \\
\text { (mill. pts.) }\end{array}$ & $\begin{array}{l}\text { Subvención } \\
\text { (mill. pts.) }\end{array}$ & $\begin{array}{c}\text { \% Subv./ } \\
\text { Inver. }\end{array}$ & $\begin{array}{c}\text { Subvención } \\
\text { Media (pts./Ha.) }\end{array}$ \\
\hline \multirow[t]{3}{*}{1986} & MNM & 1.071 & 79,640 & 37,365 & $47 \%$ & 34.873 \\
\hline & $\mathrm{MM}$ & 657 & 56,621 & 24,113 & $42 \%$ & 36.687 \\
\hline & TOTAL & 1.728 & 136,161 & 61,478 & $45 \%$ & 35.563 \\
\hline \multirow[t]{3}{*}{1987} & MNM & 142 & 10,431 & 5,029 & $48 \%$ & 35.303 \\
\hline & MM & 1.887 & 137,377 & 58,193 & $42 \%$ & 30.839 \\
\hline & TOTAL & 2.029 & 147,808 & 63,222 & $43 \%$ & 31.152 \\
\hline \multirow{3}{*}{1988} & MNM & 886 & 48,018 & 24,559 & $51 \%$ & 27.726 \\
\hline & MM & 2.797 & 224,568 & 92,792 & $41 \%$ & 33.171 \\
\hline & TOTAL & 3.683 & 272,586 & 117,351 & $43 \%$ & 31.862 \\
\hline \multirow[t]{3}{*}{1989} & MNM & 1.191 & 105,677 & 52,802 & $50 \%$ & 44.324 \\
\hline & MM & 1.911 & 199,034 & 83,393 & $42 \%$ & 43.624 \\
\hline & TOTAL & 3.102 & 304,711 & 136,195 & $45 \%$ & 43.905 \\
\hline \multirow[t]{4}{*}{1990} & MNM & 1.513 & 98,736 & 37,906 & $38 \%$ & 25.053 \\
\hline & MM & 1.625 & 189,911 & 86,233 & $45 \%$ & 52.710 \\
\hline & MAE & 70 & 12,224 & 1,412 & $11 \%$ & 20.171 \\
\hline & TOTAL & 3.118 & 300,951 & 125,511 & $42 \%$ & 40.253 \\
\hline \multirow[t]{4}{*}{1991} & MNM & 747 & 68,680 & 33,400 & $49 \%$ & 44.712 \\
\hline & $\mathrm{MM}$ & 1.143 & 145,140 & 65,850 & $45 \%$ & 57.597 \\
\hline & MAE & 48 & 10,320 & 1,160 & $11 \%$ & 24.166 \\
\hline & TOTAL & 1.938 & 224,140 & 100,410 & $45 \%$ & 51.803 \\
\hline \multirow[t]{3}{*}{1992} & MNM & 839 & 54,230 & 25,330 & $48 \%$ & 30.190 \\
\hline & MM & 1.431 & 164,600 & 75,430 & $46 \%$ & 52.111 \\
\hline & TOTAL & 2.270 & 218,830 & 100,760 & $46 \%$ & 44.387 \\
\hline \multirow[t]{4}{*}{1993} & MNM & 815 & 83,911 & 32,953 & $39 \%$ & 40.435 \\
\hline & MM & 1.709 & 202,054 & 86,325 & $43 \%$ & 50.503 \\
\hline & MAE & 64 & 19,480 & 3,756 & $19 \%$ & 58.687 \\
\hline & TOTAL & 2.588 & 305,445 & 123,034 & $40 \%$ & 47.535 \\
\hline \multirow[t]{4}{*}{$1986-93$} & MNM & 7.205 & 549,403 & 249,344 & $45 \%$ & 34.607 \\
\hline & MM & 13.172 & $1.319,385$ & 572,324 & $43 \%$ & 43.448 \\
\hline & MAE & 182 & 42,024 & 6,328 & $15 \%$ & 34.769 \\
\hline & TOTAL & 20.559 & $1.910,812$ & 827,996 & $43 \%$ & 40.273 \\
\hline
\end{tabular}

MNM: Montes no maderables. MM: Montes maderables. MAE: Montes de encinas y alcomoques.

Fuente: La agricultura y la pesca en Andalucía. Memorias anuales. Elaboraicón propia. 


\section{4.. EL PROGRAMA COMUNITARIO DE REFORESTACIÓN. SU CONCRECIÓN EN ANDALUCÍA}

El nuevo programa europeo de reforestación (Reglamento 2080/92), incluido entre las medidas de acompañamiento de la Reforma MacSharry, persigue, de forma simultánea, todos los objetivos asignados tradicionalmente al proceso reforestador: productores, protectores y socio-recreativos; a los que se añaden los de articulación territorial y la pretensión de que la opción reforestadora se convierta en una alternativa de renta, especialmente en las áreas más desfavorecidas. De ahí el que el programa se plantee las siguientes metas:

a) Disminuir el impacto negativo que pudiera derivarse de la aplicación de la reforma de la PAC en las explotaciones agrarias ${ }^{6}$.

b) Diversicar las actividades de las personas que trabajan en la agricultura y contribuir a que la reforestación constituya una alternativa de renta.

c) Mejorar a largo plazo los recursos forestales, contribuyendo al déficit de los mismos.

d) Luchar contra la erosión y por la conservación de los recursos hídricos, los suelos y la cubierta vegetal.

e) Asignar adecuadamente los usos del suelo, para fines agrícolas o forestales, manteniendo su potencial biológico y su capacidad productiva.

f) Conseguir una utilización racional de los recursos forestales renovables y el incremento de sus producciones.

g) Contribuir a la mejora de la industrialización y comercialización de los productos forestales.

h) Facilitar la generación de las condiciones socioeconómicas que eviten el desarraigo de las comunidades rurales y favorezcan su progreso, y

i) Diversificar el paisaje rural mediante la conservación y la recuperación de enclaves forestales en zonas agrícolas.

En resumidas cuentas, se pretende involucrar a los propietarios particulares en la consecución del conjunto de beneficios -tanto directos como indirectos-que los montes proporcionan. Para ello, y a diferencia de sus homónimos anteriores, el nuevo programa subvenciona la totalidad de los gastos imputables al proceso reforestador por medio de tres tipos de primas: una prima de reforestación; una prima para el mantenimiento de la superficie reforestada, percibida durante cinco años desde el inicio de la plantación y de la que quedan excluidas las reforestaciones

6. Como es sabido, uno de los objetivos que se plantean las medidas de acompañamiento es el de amortiguar los efectos que pudieran derivarse de las modificaciones operadas en las Organizaciones Comunes de Mercado: reducción de los precios de sostenimiento, endurecimiento de las condiciones desencadenantes de la intervención y reducción de las tasas de aduana y de las subvenciones a la exportación. 
que utilicen especies de crecimiento rápido; y una prima compensatoria, destinada a compensar la pérdida de ingresos derivada de la reforestación de una superficie que con anterioridad tenía un aprovechamiento agrario, que es percibida durante veinte años y que también excluye a las especies de crecimiento rápido, así como a las repoblaciones efectuadas por las entidades públicas ${ }^{7}$. Es decir, el programa incentiva las repoblaciones ejecutadas en propiedades privadas con especies de crecimiento lento; lo que igualmente lo distingue de las líneas precedentes.

El Reglamento 2080/1992 -de aplicación obligatoria en todos los países de la Comunidad, también a diferencia de programas anteriores-insta a los Estados Miembros a que presenten programas nacionales o regionales que desarrollen sus imperativos. En respuesta a ello, la Administración española (Ministerio de Agricultura, Pesca y Alimentación) publicó en los primeros meses de 1993 el Real Decreto 378/993, de 12 de marzo, que invita a su vez a las Comunidades Autónomas a que diseñen programas regionales que afectan al conjunto de su territorio o a zonas concretas del mismo. A estos efectos, la Junta de Andalucía firmó en abril de 1993 un convenio con la Administración Central donde se precisan los porcentajes de cofinanciación correspondientes al Estado español para la aplicación del programa en Andalucía ${ }^{8}$. Un mes más tarde la Consejería de Agricultura y Pesca publicó el Decreto 73/1993 de 25 de mayo, que establece las bases para la aplicación de este programa en la región.

El plan de reforestación contenido en el Decreto 73/1993 tiene una vigencia de cinco años (1993-1997), en el transcurso de los cuales se pretende reforestar una superficie de 250.000 Has.: unas 9.000 Has. durante 1993 y 60.250 Has. anuales entre 1994 y 1997. Así pues, la trascendencia que puede tener este programa en Andalucía se reafirma si comparamos estas cifras con el promedio de la superficie reforestada entre 1986 y 1993 al amparo del Programa de Fomento de las Repoblaciones Forestales en montes privados: un poco más de 2.500 Has./año, según quedó reflejado en el cuadro $n^{\circ} 5$. Asimismo, las previsiones del citado plan sobrepasan ampliamente el ritmo anual de reforestación que se marca en el Plan Forestal (en torno a las 21.000 hectáreas). Pero además, el programa analizado está teniendo una mayor aceptación entre los propietarios que sus homónimos anteriores, tal como tendremos ocasión de comprobar en las páginas que siguen.

El cuadro nº 6 refleja el importe de las primas andaluzas según la especie por la que se opte en la reforestación. Sólo hemos recogido el caso de un agricultor

7. El programa contempla, asimismo, una serie de ayudas para la mejora de las superficies ya forestadas (realización de trabajos silvícolas y construcción de cortavientos, cortafuegos y puntos de suministro de agua) y para la renovación de las plantaciones de alcornocales, que no vamos a entrar a analizar ya que no inciden en el incremento de la superficie forestal analizada en este trabajo.

8. La Unión Europea financia el $75 \%$ del presupuesto asignado al programa, tal como se deriva de la inclusión de Andalucía en la categoría de Región Objetivo 1. El $25 \%$ restante se reparte, a partes iguales, entre la Administración Central y la Junta de Andalucía. 
individual que se acoja al programa. Si las solicitudes son presentadas por agricultores asociados el importe de la prima de reforestación se incrementa en un $10 \%$ y el de las primas compensatoria y de mantenimiento en un $20 \%$. Por su parte, la cuantía de la prima compensatoria señalada en el cuadro sólo es aplicable a las solicitudes presentadas por agricultores a título principal que reforesten un máximo de 25 hectáreas; los restantes agricultores perciben una prima reducida en un $40 \%$, y en las reforestaciones que sobrepasen las 25 Has. la cuantía de la ayuda se reduce entre un 20 y un $25 \%$. La cuantía de la prima de reforestación varía, igualmente, en función de la pendiente media de la superficie a reforestar. Así, en las repoblaciones realizadas en pendientes inferiores al $5 \%$ y en suelos sin dificultad para el laboreo los importes anteriores se reducen en un $30 \%$; y si las pendientes del territorio a reforestar pasan a ser del $15 \%$, del $25 \%$ o por encima del $25 \%$, la prima de reforestación señalada en el cuadro se incrementa en un $5 \%$, en un $10 \%$ y en un $20 \%$, respectivamente.

\section{CUADRO № VI}

EL IMPORTE DE LAS PRIMAS ANDALUZAS (PTAS./HAS.)

\begin{tabular}{|c|c|c|c|}
\hline Especies & $\begin{array}{c}\text { Prima de } \\
\text { Reforestación }\end{array}$ & $\begin{array}{c}\text { Prima de } \\
\text { Mantenimiento }\end{array}$ & $\begin{array}{c}\text { Prima } \\
\text { Compensatoria }\end{array}$ \\
\hline Del anexo 1 & 175.000 & 15.000 & 20.000 \\
\hline $\begin{array}{l}\text { Del anexo } 1+25 \% \text { de los anexos } \\
2 \text { y } 3\end{array}$ & 200.000 & 20.000 & 28.000 \\
\hline Del anexo $1+50 \%$ de los anexos & 225.000 & 15.000 & 20.000 \\
\hline $\begin{array}{l}\text { Del anexo } 1+75 \% \text { de los anexos } \\
2 \text { y } 3\end{array}$ & 250.000 & 15.000 & 20.000 \\
\hline Del anexo 2 & 300.000 & 30.000 & 35.000 \\
\hline Del anexo 3 & 325.000 & 30.000 & 35.000 \\
\hline De crecimiento rápido & 120.000 & - & - \\
\hline
\end{tabular}

ESPECIES DEL ANEXO 1: Especies arbóreas cuya plantación tenga como fin principal la producción de madera a un plazo mayor de dieciocho años (mayoritariamente coníferas). ESPECIES DEL ANEXO 2: Especies arbóreas cuya plantación tenga como fin principal la restauración o creación de ecosistemas permanentes (mayoritariamente frondosas). ESPECIES DEL ANEXO 3: Especies arbóreas y arbustivas autóctonas de interés particular en ciertas zonas por motivos de producción de maderas valiosas, endemismos, peligros de extinción, etc. (incluye sabinas, nogales, endrinos, madroños, etc.). ESPECIES DE CRECIMIENTO RAPIDO: Especies arbóreas cuya producción tenga como fin principal la producción de madera en un plazo menor de dieciocho años (chopos y eucaliptos).

Fuente: Decreto 73/1993. Elaboración propia. 
En suma, si tenemos en cuenta que alrededor del $36 \%$ de la superficie andaluza sobrepasa el $15 \%$ de pendiente -en la quinta parte de la región las pendientes son superiores al $30 \%$ - (AGENCIA DE MEDIO AMBIENTE, 1990), y que en estas condiciones la agricultura adquiere un carácter marginal que convierte en más atractiva la opción reforestadora, nos encontramos con que un agricultor a título principal que reforeste $25 \mathrm{Has}$. de encinas o alcornoques -especies pertenecientes al denominado anexo 2 - en pendientes superiores al $15 \%$ podría llegar a percibir 28,750 millones de pesetas en los veinte años que aplique el programa; lo que supone una subvención media anual en torno a los 1,5 millones de pesetas. Es decir los incentivos ofertados a los propietarios particulares resultan ser lo suficientemente atrayentes como para conseguir involucrarlos en el proceso reforestador.

\section{LA APLICACIÓN DEL PROGRAMA DE REFORESTACIÓN EN ANDALUCÍA}

Los resultados de la aplicación en Andalucía del programa europeo de reforestación durante su primer año de vigencia pueden ser considerados cuando menos como exitosos: una repoblación de 10.362 hectáreas, que excede en un $15 \%$ a las 9.000 Has. previstas, y que sólo supone la cuarta parte de las más de 44.000 Has. demandadas por las solicitudes (cuadro $\mathrm{n}^{\mathrm{0}} 7$ ). Pero este éxito resulta más elocuente si recordamos que los mejores resultados de la aplicación del Programa de Fomento de las Producciones Forestales en Montes Privados raramente sobrepasan las 3.000 hectáreas de reforestación anual (cuadro $\mathrm{n}^{\circ}$ 5).

\section{CUADRO № VII \\ RESULTADOS DE LA APLICACIÓN DEL PROGRAMA DE REFORESTACIÓN EN ANDALUCÍA DURANTE 1993}

Número de solicitudes presentadas .

Superficie demandada por las solicitudes ............................................

44.040 Has.

Número de solicitudes aprobadas

Superficie de las solicitudes aprobadas

10.362 Has.

Importe de las subvenciones (millones de pesetas).......

$2.578,912$

Subvención media por solicitud (millones de pesetas)

$6.595,683$

Subvención media por hectárea (pesetas)

248.865

Tamaño medio de las explotaciones subvencionadas (Has.)

26

Fuente: La agricultura y la pesca en Andalucía. Memoria 1993. Elaboración propia.

9. 7,5 millones de pesetas de prima de reforestación (300.000 ptas./Ha. x 25 Has.) + 3,750 millones de prima de mantenimiento (30.000 ptas./Ha. x 25 Has. $x 5$ años de percepción) $+17,5$ millones de prima compensatoria (35.000 ptas./Ha. x 25 Has. x 20 años de percepción). 
El importe de las ayudas ronda los 2.600 millones de pesetas, que suponen una subvención media de 6,6 millones de pesetas por explotación y de cerca de 250.000 pesetas por hectárea. Es decir, se demuestra nuevamente el atractivo del programa en comparación con el de Fomento de las Producciones Forestales en Montes Privados, con un promedio de subvenciones en torno a las 500.000 pesetas por explotación y entre 30.000-50.000 pesetas por hectárea repoblada.

El $63 \%$ de la superficie afectada (más de 6.500 Has.) ha pasado a estar ocupada por encinas y alcornoques; en cambio, las reforestaciones con especies de crecimiento rápido apenas han tenido relevancia (cuadro $n^{\circ} 8$ ). Es decir, el programa está propiciando un vuelco en las preferencias reforestadoras de los propietarios particulares en favor de las especies no madereras, que se puede explicar por la menor cuantía de las ayudas dispensadas a las repoblaciones con chopos y eucaliptos, y por la exclusión de estas especies de la percepción de las primas compensatoria y de mantenimiento.

La escasa participación de las coníferas en las reforestaciones efectuadas durante 1993 se explica, asimismo, por la menor cuantía de las ayudas que reciben: el $60 \%$ de la prima de reforestación percibida por las frondosas, la mitad del importe de la prima de mantenimiento y el $40 \%$ de la subvención compensatoria (véase el cuadro $\mathrm{n}^{\circ}$ 6). En suma, si tenemos en cuenta que la mejor aptitud de

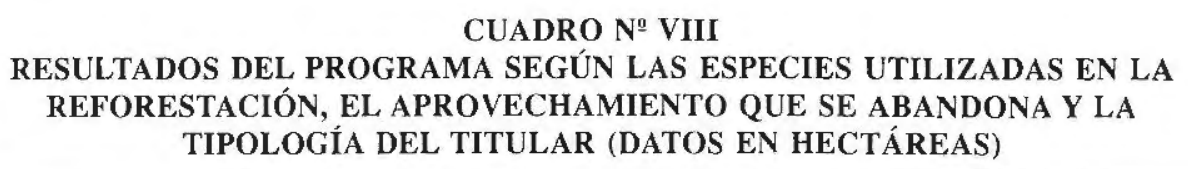
TIPOLOGÍA DEL TITULAR (DATOS EN HECTÁREAS)

\begin{tabular}{|c|c|c|c|c|c|}
\hline $\begin{array}{l}\text { Especies } \\
\text { utilizadas }\end{array}$ & Has. & $\begin{array}{l}\text { Aprovechamiento } \\
\text { que se abandona }\end{array}$ & Has. & Tipología del Titular & Has. \\
\hline 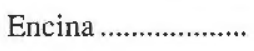 & 4.551 & Erial a pastos ........ & 4.950 & Entidades públicas ............ & 820 \\
\hline Alcornoque .............. & 2.016 & Herbáceos .............. & 3.046 & $\begin{array}{l}\text { Titulares con más del } 20 \% \\
\text { de la renta procedente de } \\
\text { la agricultura }\end{array}$ & 1.149 \\
\hline Pino Carrasco ........ & 1.115 & Pastizales .................. & 1.229 & $\begin{array}{l}\text { Agricultores a Título } \\
\text { Principal }\end{array}$ & 2.895 \\
\hline Algarrobo ................. & 1.062 & 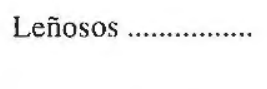 & 608 & $\begin{array}{l}\text { Otros titulares de explot. } \\
\text { agrarias }\end{array}$ & 5.498 \\
\hline Otras ......................... & 1.619 & $\begin{array}{l}\text { Montes abiertos } \\
\text { y dehesas .................... }\end{array}$ & 287 & & \\
\hline
\end{tabular}

Fuente: Idem. 
las coníferas para aguantar una insolación directa en los primeros años de desarrollo de la vegetación arbórea, y su resistencia a la sequía, las convierte en una familia especialmente adecuada para iniciar el proceso reforestador en áreas degradas $^{10}$, habremos de concluir que la reciente opción por las especies autóctonas no implica que los propietarios particulares hayan asumido entre sus competencias la preservación de los beneficios indirectos que los montes proporcionan; tan sólo han renunciado a los beneficios económicos de las especies madereras -muy escasos, por otra parte, en Andalucía- a cambio de las mayores ayudas dispensadas a las especies de turno largo.

En lo que se refiere a los aprovechamientos que se abandonan (cuadro $n^{\circ} 8$ ), destacan las superficies antes ocupadas por eriales y pastizales (más de 6.000 hectáreas, esto es, alrededor del $60 \%$ de la superficie sustituida), seguida de las tierras ocupadas por cultivos herbáceos (alrededor de 3.000 Has.). Finalmente, más de la mitad de la superficie acogida al programa (unas 5.500 Has.) pertenece a propietarios que no viven de la agricultura; lo que si bien responde a su protagonismo en la posesión de las superficies serranas andaluzas -piénsese en el papel de los propietarios absentistas en el área de Sierra Morena (ROUX, 1975, 87)-, no se ajusta a los imperativos de un programa cuyo principales destinatarios son los agricultores a título principal.

\section{A MODO DE CONCLUSIÓN}

Los resultados de la aplicación del nuevo programa de reforestación durante su primer año de vigencia llevan a que nos ratifiquemos en la hipótesis mantenida al inicio de este trabajo; a saber, la importancia que seguirá manteniendo la superficie forestal en régimen privado a pesar de las previsiones de incremento de los montes públicos que recoge el Plan Forestal. El programa está consiguiendo, asimismo, inclinar a los propietarios particulares en la utilización de especies de turno largo; pero, en nuestra opinión, este vuelco de la situación anterior se explica mejor por la mayor cuantía de las ayudas que éstas reciben, que por una presumible asunción por parte de la iniciativa privada de la oportunidad medioambiental que supone reforestar con especies autóctonas. Ello lleva a que nos preguntemos sobre el futuro de estas repoblaciones una vez que haya transcurrido el período de percepción de las ayudas.

10. De hecho, en las repoblaciones ejecutadas por la Administración Forestal primero se han plantado coníferas para luego sustituir por frondosas. Así por ejemplo, el Plan de Reforestación de 1939 consideraba la "etapa de pinares" como un requisito biológico y técnico de la restauración forestal y proponía como etapas a seguir en el proceso reforestador, primero la entrada del matorral y, posteriormente, el paso a las coníferas, a modo de antesalas deI haya y de la encina (PLAN, 1939, 53, citado por Gómez Mendoza y Mata Olmo, 1992, 19). Las recomendaciones contenidas en el Plan Forestal Andaluz indican, asimismo, la oportunidad de iniciar el proceso reforestador con la "etapa de pinares". 
En resumidas cuentas, el balance de la aplicación del reciente programa de reforestación en Andalucía aún constituye una incógnita. No obstante, como ya señalábamos en otro trabajo (SILVA PEREZ, 1995), la preservación de la superfície reforestada tras haber concluido la percepción de las ayudas debe pasar por la búsqueda de una rentabilidad económica (búsqueda de un mercado alternativo para sus subproductos, potenciación de la transformación y comercialización in situ, recuperación de antiguos aprovechamientos hoy en crisis, etc.) y/o por la habilitación de una serie de ayudas adicionales que consigan involucrar a la iniciativa privada en la preservación de los beneficios indirectos que los montes proporcionan, pues, como señalaba Montero de Burgos $(1988,60)$ "lo que hace falta no es tanto llegar a conseguir un bosque que, al final, no será rentable a su propietario y terminará abandonándolo. Lo que de verdad resulta necesario es que la sociedad provoque una rentabilidad inducida mediante una subvención anual, primando la simple existencia de un bosque, mientras éste persista".

\section{BIBLIOGRAFÍA Y DOCUMENTACIÓN}

AGENCIA DE MÉDIO AMBIENTE: Medio ambiente en Andalucía. Informes 1989 y 1993. CONSEJERÍA DE AGRICULTURA Y PESCA DE LA JUNTA DE ANDALUCÍA: La agricultura, la pesca y la alimentación en Andalucía. Memorias 1986-1993.

DECRETO 73/1993 DE LA CONSEJERÍA DE AGRICULTURA Y PESCA DE LA JUNTA DE ANDALUCÍA por el que se establece un régimen de ayudas para fomentar acciones forestales en explotaciones agrarias. BOJA n ${ }^{\circ} 57$, de 29 de mayo de 1993.

FERNÁNDEZ TOMAS, G. (1989): "El marco institucional para el desarrollo forestal", Agricultura y Sociedad $n^{\mathrm{o}} 10$, págs. 275-287.

FUSTELL, S. y SILVA, R. (1994): Reconversión de suelo agricola en forestal en zonas de agricultura marginal. Estudio elaborado por encargo de la Unión Agraria de Explotaciones Familiares de Andalucia. Ejemplar mecanografiado, 416 págs.

GÓMEZ MENDOZA, J. (1992): "El marco jurídico y la forma de explotación de los montes en España", Ponencia presentada al VI Coloquio de Geografía Rural. Madrid, págs. 79127.

GÓMEZ MENDOZA, J. y MATA OLMO, R. (1992): "Actuaciones forestales públicas desde 1940. Objetivos, criterios y resultados", Agricultura y Sociedad nº 65, págs. 15-63.

LÓPEZ ESTUDILLO, A. (1992): "Los montes públicos y las điversas vías de privatización en el siglo XIX”, Agricultura y Sociedad nº 65, págs. 65-99.

MARRACO SOLANA, S. (1989): "La política forestal comunitaria". Revista de Estudios Agro-Sociales n" 148, págs. 7-30.

MINISTERIO DE AGRICULTURA, PESCA Y ALIMENTACIÓN (1993): Anuario de Estadística Agraria de 1992. Madrid, 679 págs.

MONTERO DE BURGOS (1988): "Bases ecológicas de la reforestación", Fundación Conde del Valle de Salazar. Madrid.

Plan Forestal Andaluz, Junta de Andalucia, Consejería de Agricultura y Pesca, Instituto Andaluz de Reforma Agraria y Agencia de Medio Ambiente, 1989, 389 págs. 
PUIG, R. (1993): "La reforestación de tierras agrícolas en el marco de la política forestal europea”, Revista Montes no 33, págs.

REAL DECRETO 378/1993 del Ministerio de Agricultura, Pesca y Alimentación, por el que se establece un régimen de ayudas para fomentar inversiones forestales en las explotaciones agrarias y acciones de fomento de los bosques en zonas rurales. BOE $n^{0} 76$ de 30 de marzo de 1993.

REGLAMENTO (CEE) nº 2080/92 del Consejo, por el que se establece un régimen comunitario de ayudas a las medidas forestales en la agricultura. DOCE $n^{\circ}$ L 215 de 30 de julio de 1992.

ROUX, B. (1975): Crisis agraria en la sierra andaluza. Instituto de Desarrollo Regional. Universidad de Sevilla, 224 págs.

SILVA PÉREZ, R. (1995): "De la deforestación a la reconversión de terrenos agrícolas en forestales. Un análisis crítico". Actas del XIV Congreso Nacional de Geografía (en prensa).

SUMPSI VIÑAS, J.M. (1991): "Crisis agraria y política forestal", Revista de Estudios AgroSociales, $\mathrm{n}^{\mathrm{O}} 158$, págs. $57-81$. 